\title{
A study on different micro-irrigation techniques for mitigating water stress of immature rubber (Hevea brasiliensis) plants
}

\author{
S A Nakandala*, N M C Nayanakantha*, P Seneviratne*, M N de Alwis* \\ and $\mathrm{D} L \mathrm{~N}$ de Zoysa*
}

* Rubber Research Institute of Sri Lanka, Dartonfield, Agalawatta

\begin{abstract}
The Intermediate and Dry Zones of Sri Lanka have been targeted in expanding the rubber plantations with a view to expand the extent under planting to achieve national targets in natural rubber production. However, climatic conditions of these regions are suboptimal for growing of rubber. The mid-year dry period in these areas extends from June to September and as a result, plants experience a severe water stress especially in nursery and immature period. Therefore, this study was carried out in the Kilinochchi District, which belongs to the Agro-ecological Zone, DL3 in order to assess the performance of micro-irrigation techniques for immature or young rubber plants. Two micro-irrigation systems; viz. drip and spray jet were tested under three soil moisture depletion levels; 30, 50 and 70\% of available soil moisture.

Results showed that the growth of immature young rubber plants were highly responsive to moisture depletion levels and micro-irrigated systems. It was found that both drip and spray jet irrigation systems performed well in supplying water at $30 \%$ depletion level when compared to the depletion levels of 50 and 70\%. Water stress is created by $70 \%$ depletion level with decreased chlorophyll content, stomata closure and increase in leaf temperature. Adequate irrigation at 30\% depletion level in both systems resulted significant increment of chlorophyll content $(p<0.05)$. There was significant increment in chlorophyll content in plants which were irrigated with spray jet system when compared to drip system. Plants which were irrigated at $30 \%$ depletion level regulated higher stomatal conductance even under higher temperatures during mid-day period.
\end{abstract}

Key words: chlorophyll, depletion, drip, immature rubber, micro-irrigation, spray jet

\section{Introduction}

Rubber is one of the main plantation crops in Sri Lanka with a total extent around 130.3 thousand hectares while the extent under tapping was around 98.6 thousand hectares in 2017 (Anon., 2017). In order to meet the demand for raw rubber, it is needed to increase raw rubber production through planting of genetically improved planting materials and continuously expanding the area under planting. There has been a continuous replanting rate of $3 \%$ or above as acceptable level, which indicates the average growth of the industry (Seneviratne, 2005). The 
increase in rubber extent was 1500 ha in 2017 due to the extent of new planting in traditional rubber growing areas (Anon., 2017). However, further expansion of rubber cultivation in the Western part of the country is limited largely due to non availability of lands due to urbanization and industrialization. Therefore, to meet the increasing global demand for natural rubber and considering its limited scope of expansion in the traditional areas, attempts are being made to extend its cultivation to marginally suitable areas in Dry and Intermediate Zones in the country. This initiative on cultivation of rubber in the Dry Zone is expected to improve the livelihoods of people who were entangled in thirty years' civil war. Rubber is a crop which has its all operations connected with the rainfall pattern. Wijesuriya et al. (2013) reported that the Agro-ecological regions, DL1, DL2 and DL3 in the Dry Zone are vulnerable to prolonged droughts during March to August in most of the years. Drought stress poses adverse effects on immature rubber including morphological and plant physiological changes. Receiving a rainfall below 500 $\mathrm{mm}$ over six consecutive months is considered detrimental to growing of rubber (Yogaratnam, 2001). High evaporation from the soil surface associated with low relative humidity, high temperature and wind conditions, affect the new plantings adversely.

Irrigation and soil conditioning are therefore necessary for the drier areas to ensure high quality plants with healthy growth especially under immature stage. To improve the early establishment and survival of immature plants, it is very important to have proper field water management practices with the selection of a proper irrigation method especially for the dry period of the year. Literature has reported that with irrigation the immaturity period in the dry region in India could be reduced from more than 10 years to six years (Devakumar et al., 1998).

Irrigation technology has developed rapidly from border to micro irrigation and from manual to automation, over the last two decades. Micro irrigation systems are convenient with a potential for saving water and assures producing large and steady crop yields. The water availability, type of soil, topography of the land and labour availability determine the selection of the irrigation system (Nakandala et al., 2008).

Mini sprinkler or spray jet and drip irrigation systems are two kinds of micro irrigation systems now widely used in many crops. The rate of applying water in a micro irrigation system is an important factor which governs moisture distribution in the soil profile. Precise irrigation schedule with the selection of a micro irrigation system and irrigation interval together with the desired depletion level will improve the water use efficiency and growth of plants especially in the immature phase.

Keeping the above facts in view, the growth of immature rubber plantations in the Dry Zone of the country under microirrigation was studied in irrigated rubber cultivation. The objective of the study was to assess the performance of drip and mini sprinkler or spray jet systems at different soil moisture depletion levels in order to evaluate the responses on the 
S A Nakandala et al.

physiological and morphological growth performances of immature rubber plants.

\section{Materials and Methods}

Two types of micro irrigation systems (drip and mini sprinkler or spray jet systems) were installed in a newly established smallholder rubber field with an extent of 0.4 ha in Kilinochchi District of the Dry Zone in 2018. The system was designed with main, sub main and lateral lines from the water source to the experimental site. To maintain the required operating pressure in the system, the main line was connected with the pumping source along with a gate valve for regulating water as per the requirement of the treatment. Average discharge rates of drip and micro spray jet were eight litres per hour (lph) and 16 lph, respectively. Two on-line drippers were installed between the plant and one spray jet sprinkler was setup near the plant. The time of irrigation was adjusted in both systems in order to supply the same volume of water to each plant. A six months old rubber field which was established in November, 2017 was used for the experiment with two irrigation systems. Three levels of moisture depletion; viz. 30\%, 50\% and $70 \%$ were tested under drip and spray jet irrigation systems according to a Randomized Complete Block Design (RCBD) with three replications. Morphological and physiological attributes of plant growth were gathered throughout the study period. Moisture availability of the soil to maintain each depletion levels was measured by using a Theta probe device and moisture meter (Delta $\mathrm{T}$ Model DL6). Morphological attributes such as stem diameter, plant height, leaf area and number of leaves of each treatment were gathered in monthly periods. Physiological measurements were taken on chlorophyll content and stomatal conductance of plants.

Field capacity (FC) and permanent wilting point (PWP) of the soil in the experimental site were measured prior to irrigation. Undisturbed samples at $10 \mathrm{~cm}$ soil depth were taken daily to measure soil moisture near the treatment plants in order to schedule the irrigation interval along with the depletion levels. At each depletion level, two irrigation systems were operated to a maximum of one hour until the soil reached the field capacity. Irrigation was not given to the experimental field at the times of rainfall. Plant stem diameter and plant height were measured once a month as morphological parameters. Leaf area was determined as an on-site measurement by using a portable leaf area meter (Delta T MK2). Fifteen plants in each treatment in three replicates were taken for measurements. Total number of leaves of the plants was counted together with leaf area at monthly intervals.

Plant physiological parameters such as; stomatal conductance, chlorophyll content and leaf temperature were measured once a month throughout the study period. Stomatal conductance and leaf temperature were measured by a portable porometer (Delta $\mathrm{T}$ AP4). Measurements were taken from the top mature leaf and middle leaflet of each treatment. Leaf chlorophyll content was measured by non-destructive method using a chlorophyll meter (SPAD 502DL Plus). The meter gives chlorophyll 
content as an index value (SPAD value) which is proportional to the amount of chlorophyll content of leaves. Average measurements were taken from one of the top mature leaves.

Data were gathered in rainless dry months. Statistical analysis was done using analysis of variance followed by mean separation employing Duncan's Multiple Range Test (DMRT), at a probability level of 0.05 SAS statistical software package - version 9.0 (SAS Inc., USA) was used to analyze data.

\section{Results and Discussion \\ Moisture depletion pattern}

Figure 1 shows the soil moisture depletion patterns of soils under treatment plants. Daily moisture measurements were taken as percentage of moisture in the soil under volume basis.

Field capacity and PWP of soils were 18.7 and $4.7 \%$, respectively. Moisture depletion patterns indicate the depletion of water at each irrigation interval with respective to each depletion level i.e.; $30 \%, 50 \%$ and $70 \%$. Moderate to severe drought condition was created with the levels at 50 to $70 \%$ depletion levels and irrigation at $30 \%$ depletion level, once in two days interval minimized the drought stress of the treatment plants.

\section{Morphological responses of immature rubber plants on micro-irrigation}

Two micro irrigation systems (drip irrigation system, spray jet irrigation system) were tested under three levels of depletion and stem diameter, height, leaf area and number of leaves were measured as morphological growth attributes of immature plants during the first year of field planting. Table 1 shows the variation in morphological characters of eight months aged plants according to the different depletion levels under two micro irrigation systems after three months of commencement of irrigation. According to Table 1, the application of two micro irrigation systems at 30\% depletion level has significantly ( $\mathrm{p}<$ 0.05 ) increased all growth parameters of eight months old plants irrespective of the type of micro irrigation systems. Plant diameter increased with high moisture level in the soil. Higher depletion levels (i.e. 50\% and 70\%) resulted drought stress to the plants and showed significantly low $(\mathrm{p} \leq 0.05)$ plant stem and height. Total leaf area and number of leaves in a plant at 30\% depletion level, showed a significantly higher value $(\mathrm{p} \leq 0.05)$ irrespective of two micro irrigation systems than that of the drought stressed plants at 70\% depletion in both irrigation systems. 


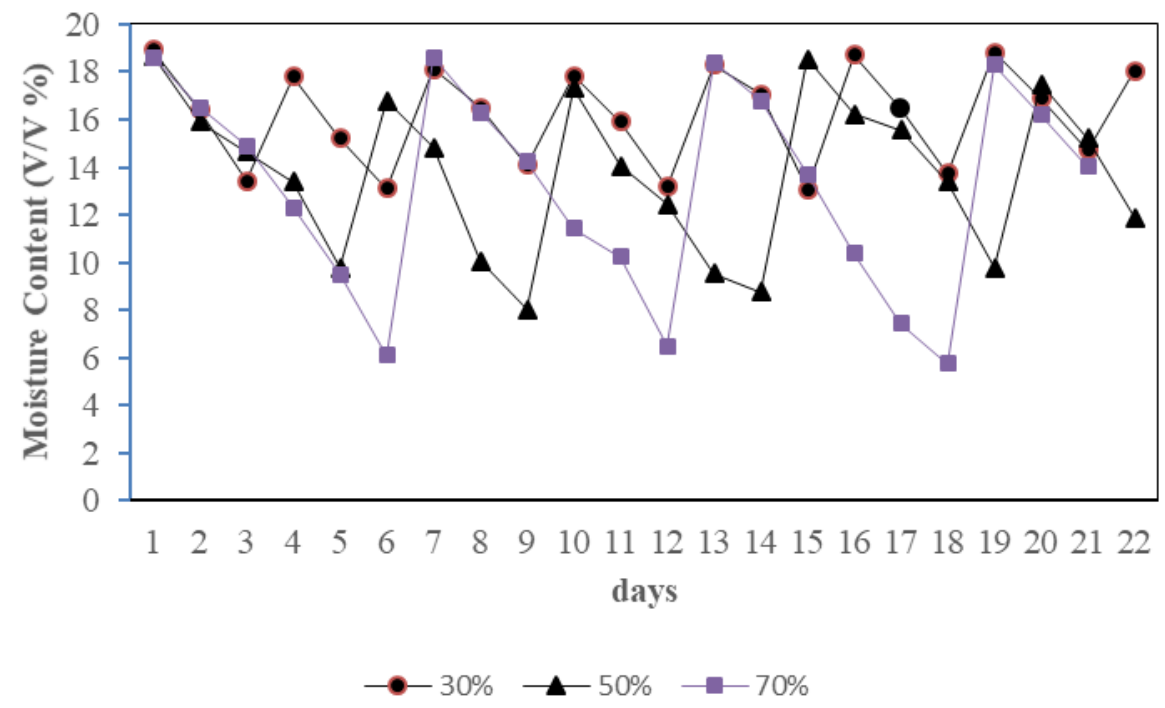

Fig. 1. Moisture depletion patterns of different moisture depletion levels

Morphological attributes of young plants showed that the growth of immature rubber plants was highly responsive to moisture depletion levels in irrigated agriculture. It has found that drip and spray jet irrigation systems performed well in supplying water to the soil and significantly increased $(\mathrm{p} \leq 0.05)$ growth of plants at $30 \%$ depletion level when compared to higher depletion levels. Plants irrigated with regular intervals at $30 \%$ depletion level in both systems provided necessary water requirement for plant growth (Table 1). As evident in the Table 1, spray jet system creates a cooler micro- environment to the plants that enables to grow plants with less stress compare to the drip irrigation system. Similar results were obtained for leaf area and number of leaves per plant. There was significant decline of leaf area $(\mathrm{p} \leq 0.05)$ in drought stressed plants at $70 \%$ depletion level due to drying or senescence of lower mature leaves and wilting of new leaves in upper whirls. Scorching or drying of leaf margins, whole leaves of rubber plants caused by the direct effect of high temperature and water deficit have reduced the total number of leaves and leaf area per plant (Samarappuli et al., 1998). 
Micro-irrigation for mitigating water stress of immature rubber

Table 1. Morphological characters of eight months rubber plants on depletion levels and two micro irrigation systems

\begin{tabular}{lccccc}
\hline Type & $\begin{array}{c}\text { Depletion } \\
\text { level }(\boldsymbol{\%})\end{array}$ & $\begin{array}{c}\text { Diameter } \\
(\mathbf{m m})\end{array}$ & $\begin{array}{c}\text { Height } \\
(\mathbf{c m})\end{array}$ & $\begin{array}{c}\text { Leaf area } \\
\left(\mathbf{c m}^{2}\right)\end{array}$ & $\begin{array}{c}\text { Leaf count } \\
(\text { nos.) }\end{array}$ \\
\hline Drip & 30 & $20.6^{\mathrm{a}}$ & $141.0^{\mathrm{a}}$ & $2862.5^{\mathrm{a}}$ & $43.8^{\mathrm{a}}$ \\
& 50 & $17.5^{\mathrm{b}}$ & $120.0^{\mathrm{b}}$ & $2027.6^{\mathrm{b}}$ & $38.7^{\mathrm{b}}$ \\
& 70 & $15.5^{\mathrm{c}}$ & $110.9^{\mathrm{b}}$ & $1368.1^{\mathrm{c}}$ & $24.4^{\mathrm{c}}$ \\
\hline Spray & 30 & $21.6^{\mathrm{a}}$ & $183.9^{\mathrm{a}}$ & $2532.8^{\mathrm{a}}$ & $39.6^{\mathrm{a}}$ \\
jet & 50 & $16.5^{\mathrm{b}}$ & $100.1^{\mathrm{b}}$ & $2367.5^{\mathrm{b}}$ & $32.7^{\mathrm{b}}$ \\
& 70 & $14.0^{\mathrm{c}}$ & $95.1^{\mathrm{b}}$ & $1559.1^{\mathrm{c}}$ & $25.1^{\mathrm{c}}$
\end{tabular}

(Means with the same letter along the column are not significantly different at 0.05 probability level)

\section{Physiological responses}

Leaf chlorophyll content is a major component of the photosynthetic system. Figure 2 shows the variation of chlorophyll content of eight months old plants under drip and spay jet irrigation at different depletion levels. There was a significantly lower chlorophyll content per plant $(\mathrm{p} \leq 0.05)$ at drought stressed condition of $70 \%$ depletion level, when compared with all other treated plants. Figure 2 shows that the plants which were irrigated with both systems under $30 \%$ depletion level resulted higher chlorophyll content. When compared to the two systems irrespective of depletion levels, there was an increment in chlorophyll content in plants which were irrigated with spray jet system (Fig. 2).

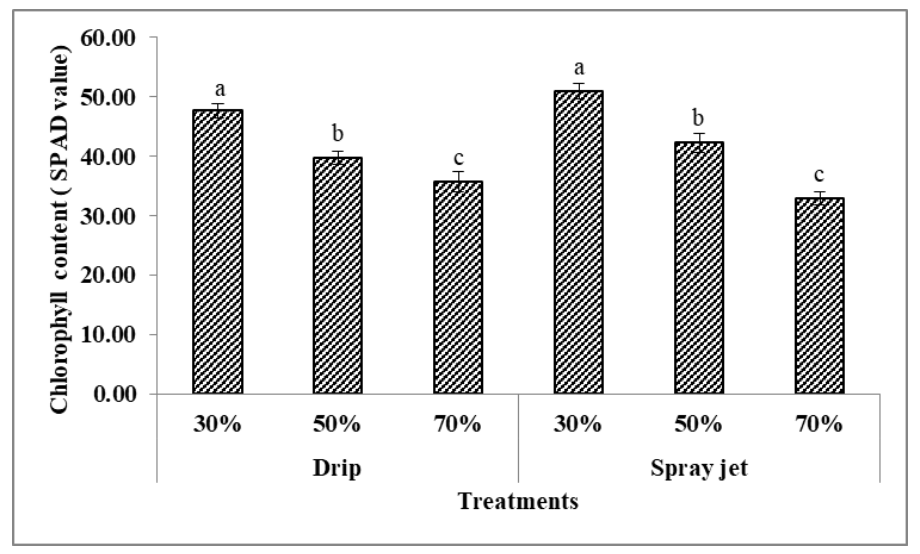

Fig. 2. Chlorophyll content of immature rubber plants of eight months under two irrigated conditions at different depletion levels of 30,50 and 70\% (Means with the same letter are not significantly different at the probability level, 0.05 ) 
S A Nakandala et al.

Chlorophyll content as photosynthetic pigments is important to the plant mainly for harvesting light and production of organic compounds. Drought stress at higher levels of depletion causes large decline in chlorophyll content and low concentrations of chlorophyll pigments can directly limit photosynthetic potential and hence, primary production (Anjum et al., 2011).

Stomatal regulation is a key process that involve in the photosynthesis process. Measurement of stomatal conductance varied with leaf temperature and influence of decreasing water availability in the soil. Figure 3 shows the variation in stomatal conductance of plants under drip irrigated (a) and spray
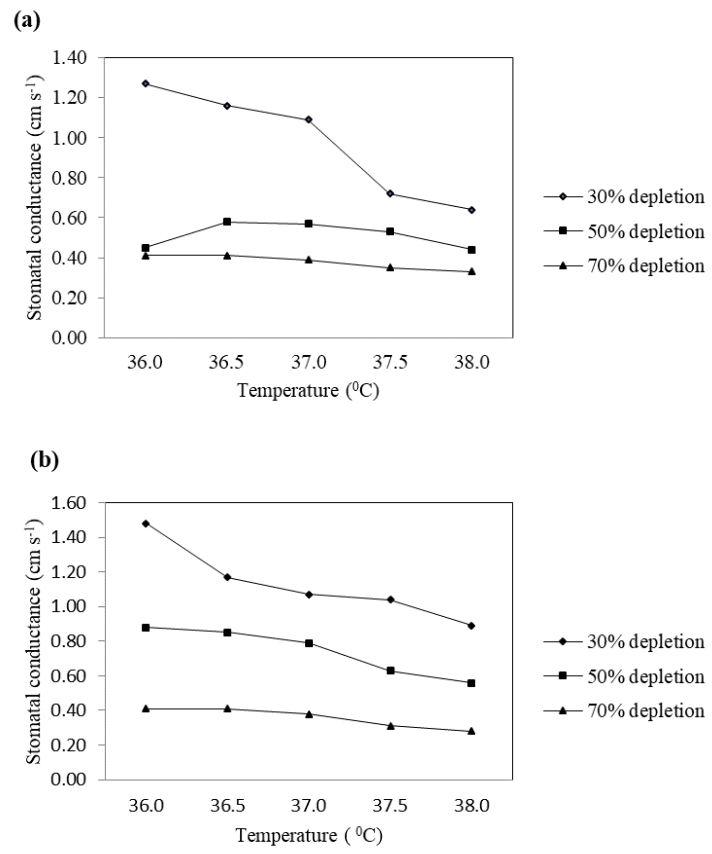

Fig. 3. Stomatal conductance under leaf temperature of eight months old plants after three months of irrigation (a) drip irrigation system under three depletion levels and (b) spray jet irrigation system under three depletion levels (30,50 and 70\%) jet irrigated (b) on different temperatures of leaf surface. Plants which were irrigated with regular intervals at $30 \%$ depletion level, regulated higher conductance even at higher temperatures during mid-day. However, plants had its defense mechanism on stomatal opening and closing under high-temperature regimes (Habibi, 2012). Stomatal conductance of plant cells under higher depletion levels decreases progressively with increase of leaf temperature (Fig. 3 ). Figure $3 b$ shows higher values for stomatal conductance in spray jet system. This may be due to mini sprinkling of water at the base of plants under spray jet system. 
Micro-irrigation for mitigating water stress of immature rubber

\section{Conclusion}

A significant impact on micro irrigated cultivation has been observed on physiological and morphological growth performance of immature plants, alleviating water stress of young rubber plants.

Irrigation scheduling at $30 \%$ of soil moisture depletion level gives significantly effective results on morphological and physiological growth of immature rubber plants under microirrigated conditions. Water stress was formed by $70 \%$ depletion level and differences in two types of micro irrigation systems at each deletion level were not significant in this study.

\section{References}

Anjum, S A, Xie, X, Saleem, M F, Man, C and Wang, L (2011). Morphological, physiological and biochemical responses of plants to drought stress. African Journal of Agricultural Research 6(9), 2026-32.

Anon. (2017). Rubber Sector. Plantation Sector Statistical Pocket Book. Ministry of Plantation Industries, Colombo, Sri Lanka.

Devakumar, A S, Sathik, M B M, Jacob, J and Annamalainathan, K (1998). Effects of atmospheric and soil drought on growth and development of Hevea brasiliensis. Journal of Rubber Research 1(3), 190-198.

Habibi, G (2012). Exogenous salicylic acid alleviates oxidative damages of barley plants under drought stress. Acta biologica Szegediensis 56, 57-63. Available at: http//www.sci.u.szeged.hu/ ABS.
Nakandala, S A, Senaviratne, $\mathrm{P}$ and Pathirana, P D (2008). A study on irrigation systems for rubber nurseries in the Intermediate Zone in Sri Lanka. In: Proceedings of the Second Symposium on Plantation Crop Research - Export Competitiveness through Quality Improvements. (Eds. N $\quad \mathrm{P}$ A $\mathrm{D}$ Nainanayake and $\mathrm{J}$ M D T Everard). Coconut Research Institute, Lunuwila, Sri Lanka. 307-312.

Samarappuli, L and Yogaratnam, N (1998). Tolerance of rubber plantations to drought and atmospheric warming: A review. Journal of the Rubber Research Institute of Sri Lanka 81, 51-67.

Senaviratne, P (2005). Production of planting material for rubber replanting and new planting programmes in Sri Lanka. Bulletin of the Rubber Research Institute of the Sri Lanka 46, 17-24.

Wijesuriya, W, Dissanayake, D M A P, Herath, H M L K, Karunarathne, S B, Jeewanthi, P W, Kulasekera, B R and Gurusinghe, C S (2013). Use of rainfall pattern for efficient management of rubber plantations Central and Northern provinces of Sri Lanka. Journal of the Rubber Research Institute of Sri Lanka 93, 72-88.

Yogaratnam, N (2001). Land suitability evaluation, selection and soil conservation. In: Handbook of Rubber, Volume 1, Agronomy, 1-11 (Eds. L.M.K. Tillekeratne and A Nugawela), Rubber Research Institute of Sri Lanka.

Address for correspondence: Dr (Mrs) S A Nakandala, Research Officer, Plant Science Dept., Rubber Research Institute of Sri Lanka, Dartonfield, Agalawatta, Sri Lanka. e-mail: sanakandala@gmail.com 